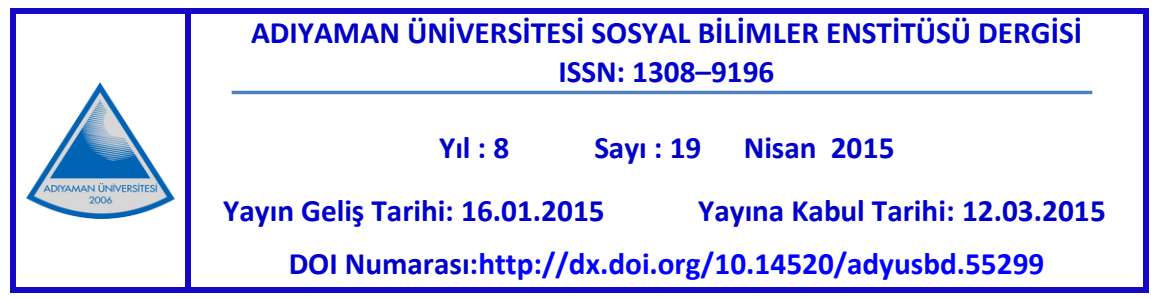

\title{
ILKOKULLARDA TEKNOLOJi EĞiTiMi
}

\section{Sayım AKTAY*}

\author{
Emel GÜVEY AKTAY ${ }^{* *}$
}

\begin{abstract}
$\ddot{O} z$
Bu çalışmanın amacı, ilkokullarda teknoloji eğitiminin yerini sorgulamak ve bir ders ya da içerik olarak teknolojinin nasıl yer alması gerektiğini sınıf öğretmeni görüşlerine dayalı olarak ortaya koymaktır. ilkokullarda teknolojinin yerini belirlemeyi amaçlayan bu araştırmada, nitel araştırma deseni benimsenmiştir. Katılımcılar, amaçlı örnekleme yöntemlerinden ölçüt örnekleme yoluyla belirlenmiştir. Araştırmanın katılımcıları, 20132014 öğretim yılının bahar döneminde Giresun il merkezinde yer alan ilkokulların 4. sınıflarında görev yapan 15 sınıf öğretmenidir. Araştırma verileri yarı yapılandırılmış görüşme soruları ile toplanmış, verilerin çözümlenmesinde betimsel analiz kullanılmıştır. Araştırmada, günümüzde ilkokullardaki teknoloji eğitiminin çoğunlukla yetersiz olduğu ya da hiç yer almadığı ortaya çıkmıştır. Bunun yanı sıra ilkokulda öğretmenlerin bir kısmı teknoloji eğitimi etkinlikleri yapmazken; bir kısmı ders etkinlikleri içerisinde teknoloji ile internetin yararları ve zararları, klavye kullanma, dosya oluşturma, ofis programları kullanımı gibi konularda eğitim verdikleri sonucuna ulaşılmıştır.
\end{abstract}

Anahtar Kelimeler: Illkokul, teknoloji öğretimi, teknoloji.

\footnotetext{
${ }^{*}$ Arş.Gör.Dr. Giresun Üniversitesi Eğitim Fakültesi, sayimaktay@gmail.com

Arş.Gör. Anadolu Üniversitesi Eğitim Fakültesi, meguvey@gmail.com
} 


\title{
TECHNOLOGY EDUCATION IN PRIMARY SCHOOLS
}

\begin{abstract}
The main purpose of this study is to question the place of technology in primary schools and reveal how it must be included as a lesson or content, based on the classroom teachers' opinions. In this study, which aims to determine the place of technology in primary schools, qualitative research model has been adopted. Participants are determined through criterion sampling which is one of the purposeful sampling methods. The population of the study includes the classroom teachers who teach the fourth grade primary school students in the city center of Giresun, in 2013-2014 spring term. The data of the study was gathered through semi-structured interview questions. Descriptive analysis was utilized in analyzing the data of the study. It was found in the study that the current technology education in primary schools is either mostly inadequate or unavailable. While some of the teachers in primary schools do not conduct technology education activities, the others provide education for such fields as benefits and harms of the Internet, keyboard usage, file creation and office programs, within classroom activities.
\end{abstract}

Keywords: Primary school, technology education, technology.

\section{GiRiş}

Günümüzde bilim ve teknolojinin hızla gelişmesiyle birlikte, eğitim kurumları da kendilerinin ve paydaşlarının teknolojiyi kullanabilecek yeterlikte olmalarını sağlama çabası içine girmektedir. Bu bağlamda, eğitim kurumları bireylerin gerek eğitiminde gerekse eğitim aracı boyutunda eğitim teknolojilerini bütünleştirme yoluna gitmektedir.

Günümüzde bilgisayar ve internet teknolojileri, bilgiyi arama ve ulaşmada yadsınamaz biçimde önemli bir yer edinmiştir. İnternet (Odabaşı, Kabakçı ve Çoklar, 2007) güncel bilgiye hem kolay hem de hızlı bir biçimde ulaşmayı olanaklı kıldı̆̆ı gibi; metin, resim ve ses gibi farklı bilgi formatlarından yararlanmayı da sağlayabilmektedir. 
Öğrencilerin, 6 yaşından itibaren fareyi kullanma, bilgisayarda oyun oynama, oyun sırasındaki süreçlerde karşııına çıkan görevleri yerine getirme gibi teknolojik becerilerde yetkin durumda olduğu görülmektedir. 7 ile 9 yaş arasındaki öğrencilerde, internet teknolojilerine ve internetteki yasaklara ilgilerinin arttığı görülmektedir. Bu öğrencilerin büyük çoğunluğunun internet kullanmayı kendi ailelerinden ya da kendi kendilerine öğrenmek durumunda kalmaktadırlar. 10-13 yaş arasında ise internet teknolojileri konusunda öğrenciler artık büyük miktarda bilgiye sahip olup internette bilgi arama, arkadaşlık siteleri gibi alanlara yoğunlaşmakta ve müzik dinleme, e-posta gönderme gibi etkinlikleri kolaylıkla yapabilmektedir (Şahin, 2014). Türkiye İstatistik Kurumu (TÜIK) tarafından 2013 yılında gerçekleştirilen "Hanehalkı Bilişim Teknolojileri Kullanım Araştırması"nda 06-10 yaş grubu çocuklarda bilgisayar ve internet kullanmaya başlama yaş ortalamasının 6 olduğu ortaya çıkmışır. Ayrıca bu gruptaki çocuklar cep telefonu kullanmaya da ortalama 7 yaşında başlamakta ve \%30,7 oranında cep telefonunu internete girmek için kullanmaktadır (Türkiye istatistik Kurumu, 2013). Sakarya, Tercan ve Çoklar tarafından (2011) yapılan bir araştırmada buna uygun olarak ilköğretim öğrencilerinin bilgi kaynağı olarak kullandıkları en önemli kaynak internet olmuş ve çalışma kitabı, ansiklopedi ve ders kitabı gibi kaynaklardan çok daha öncelikli bir yer edinmiştir. Bu öğrencilerin büyük çoğunluğunun interneti bilgi aramak, oyun, haberleşme, film izleme, müzik dinleme, haber takip etme gibi nedenlerle kullandığı görülmüştür.

Teknoloji kullanımı öğrencilerin yaptıkları etkinlikleri daha eğlenceli hale getirmekte ve öğrencilerin yaşamlarında önemli bir yere sahip olmaktadır. Ayrıca, öğrencilerin bilgisayar teknolojilerini kullanarak yaptıkları çalışmalarda, öğrenme deneyimleri daha zevkli bir hale gelmektedir (Murphy ve Beggs, 2003). Öğrencilerin internet ve bilgisayar gibi teknolojiler konusunda birtakım bilgilere ve yeterliklere sahip olmaları ve bu teknolojileri kullanmaktan memnun 
olmalarının, bu teknolojileri eğitim amaçlı olarak kullanmalarını etkilediğini söylemek mümkündür.

Öğrencilerin bilgisayar ve internet gibi teknolojileri kullanırken karşılaşabilecekleri birçok tehlike bulunmaktadır. Öğrenciler, virüsler, solucanlar ve spamlar gibi birçok zararlı yazılımların yanı sıra uygun olmayan içerikler ve çevrimiçi olarak kendilerine ulaşabilecek güvenliklerini tehdit eden kişiler gibi tehlikelere karşı karşıya kalabilmektedir (Odabaşı, Kabakçı ve Çoklar, 2007). Öğrencilerin interneti nasıl ve hangi yollarla öğrendiğine ilişkin olarak, Ersoy (2002) tarafından ilköğretim 4. ve 5. sınıf öğrencileriyle yapılan bir çalışmada, öğrencilerin interneti resmi bir kurum yerine, en çok ailelerinden ve kendi kendilerine öğrenmiş oldukları ortaya çıkmıştır. Ayrıca, öğrenciler haftada ortalama 30 dakika ile 5 saat arası internete bağlı kalmakta ve internetle ilgili bilgileri yine en çok internet üzerinden elde etmeleri, internetin öğrencilerin yaşamlarında önemli bir yere sahip olduğunu göstermektedir.

İnternetin ve günümüz teknolojilerinin çocuklar arasında yaygın kullanılması, eğitim ortamlarında ve eğitim programlarında uygun koşulların oluşturulmasını gerektirmektedir. Bütün öğrencilerin fen ve teknoloji okuryazarı olarak yetişmesi amacıyla (TTKB, 2004), 2004-2005 öğretim yılında Fen Bilgisi dersinin yerini alan Fen ve Teknoloji dersi (MEB, 2004) “teknoloji” bölümünün, 20132014 öğretim yılı itibariyle çıkarılmasıyla Fen Bilimleri haline gelmiştir (MEB, 2014). Illkokul programları incelendiğinde, programda "Bilgisayar" dersi gibi teknoloji öğretimine odaklanan bir dersin yer almadığı görülmektedir. Ayrıca, seçmeli derslerin kaldırılması ile “ilköğretim Seçmeli Bilgisayar (1-8. Sınıflar) Dersi Öğretim Programı" da kaldırılmıştır.

Alanyazın incelendiğinde, öğrencilerin daha henüz okula başlama yaşında bilgisayar ve internet gibi günümüz teknolojileri ile tanışmış ya da tanışmaya başlamış olduğu görülmektedir. Günümüzde bu teknolojiler öğrencilere zarar 
verecek birçok özellik içermekte ve öğrencileri tehlikelere açık hale getirmektedir. Aynı zamanda bu teknolojiler, öğrencilerin eğitim ve öğretim etkinliklerinde de kullanabildikleri ve en çok tercih ettikleri eğitim kaynakları arasında yer almaktadır. Dolayısıyla, öğrencilerin bu tür teknolojileri kullanmayı öğrenmeleri, bu tür teknolojileri nasıl kullanmaları gerektiği bilincine sahip olmaları ve erken yaşlarda bu teknolojilere ilişkin nitelikli bir eğitim verilerek, öğrencilerin doğru kazanımlarla yetişmeleri oldukça önemlidir.

$\mathrm{Bu}$ çalışmanın amacı, ilkokullarda teknoloji eğitiminin yerini sorgulamak ve teknoloji eğitimine ilişkin sınıf öğretmenlerinin görüşlerini ortaya koymaktır. Bu temel amaç bağlamında aşağıdaki sorulara yanıt aranmıştır:

- Sınıf öğretmenlerine göre ilkokullarda teknoloji eğitimi nasıldır?

- Sınıf öğretmenleri teknoloji eğitimini nasıl ve hangi bağlamlarda gerçekleştirmektedir?

- Teknoloji bağlamında sınıf öğretmenlerinin yeterliği nasıldır?

- Sınıf öğretmenleri, ilkokul öğrencilerinden ne tür teknolojik becerilere sahip olmalarını beklemektedir?

- Sınıf öğretmenlerinin teknoloji öğretiminin ilkokul programlarında yer almasına ilişkin görüşleri nelerdir?

- Sınıf öğretmenlerine göre, Fen ve Teknoloji Dersinin Fen Bilimleri olarak değişmesinin teknoloji eğitimine etkileri nelerdir?

- Sınıf öğretmenleri, ilkokullarda teknoloji öğretimi bağlamında ne tür sorunlar yaşamaktadır?

- Sınıf öğretmenleri, ilkokullarda teknoloji öğretimi bağlamında yaşanan sorunlara ne tür öneriler getirmektedir? 


\section{YÖNTEM}

\subsection{Araştırma Deseni}

İlkokullarda teknolojinin yerini belirlemeyi amaçlayan bu araştırmada, nitel araştırma deseni benimsenmiştir. Nitel araştırma (Tavşancıl ve Aslan, 2001; Yıldırım ve Şimşek, 2013) gözlem ve görüşme gibi veri toplama yöntemlerinin kullanıldığı, algıların ve olayların doğal ortamda gerçekçi ve bütüncül bir biçimde ortaya konmasına yönelik nitel bir sürecin izlendiği araştırma yöntemidir.

\subsection{Araştırmanın Katılımcıları}

Araştırmanın katılımcıları, 2013-2014 öğretim yılının bahar döneminde Giresun ili merkezinde yer alan ilkokulların 4. sınıflarında görev yapan sınıf öğretmenleridir. Katılımcılar, amaçlı örnekleme yöntemlerinden ölçüt örnekleme (Patton, 1987) yoluyla belirlenmiştir. Araştırmaya katılan sınıf öğretmenlerinin görev yaptıkları okulların sosyo ekonomik durumları, bu okullarda en az iki 4. sınıf şubesinin bulunması, öğretmenlerin en az 10 yıl ve üzeri mesleki deneyime sahip olmaları ve 4. sınıfları en az bir kez okutmuş olmaları ölçütleri dikkate alınmıştır. Buna göre, araştırma kapsamında farklı sosyo ekonomik düzeyde yer alan ilkokullar seçilmiş ve bu okullarda görev yapan ve araştırmaya gönüllü olarak katılmak isteyen 4. sınıf öğretmenleri katılımcı olarak belirlenmiştir.

\subsection{Veri Toplama Araçları}

Araştırmanın verileri yarı yapılandırılmış görüşme soruları ile toplanmıştır. Yarı yapılandırılmış görüşmeler, önceden belirlenmiş sorulardan oluşmaktadır. Araştırmacı herhangi bir sırayı takip ederek soruları sormaktadır. Bunun yanı sıra araştırmacı, görüşme yaptığı kişinin ne söylediğine ilişkin yeni sorular yöneltebilirken bazı soruları da sormayabilir (Runswick-Cole, 2011). Veri 
toplama aracı için öncelikle taslak görüşme soruları hazırlanmış ve 2 uzmanın görüşüne sunulmuştur. Uzmanların görüşleri doğrultusunda yeniden düzenlenen yarı yapılandırılmış görüşme soruları, 1 öğretmen adayı ile pilot görüşmede sorulmuştur. Pilot görüşmeden elde edilen dönütler doğrultusunda görüşme sorularına son hali verilmiş ve 15 sınıf öğretmeniyle görüşmeler gerçekleştirilmiştir. Görüşmeler okul ortamında ses kaydı yapılarak gerçekleştirilmiştir.

\subsection{Verilerin Analizi ve Yorumlanması}

Araştırma verilerinin çözümlenmesinde betimsel analiz kullanılmıştır. Elde edilen veriler temalar biçiminde düzenlenmiştir. Betimsel analiz; betimsel analiz için bir çerçeve oluşturma, tematik çerçeveye göre verilerin işlenmesi, bulguların tanımlanması ve bulguların yorumlanması aşamalarından oluşmaktadır (Yıldırım ve Şimşek, 2013).

Araştırmada elde edilen verilerin analizinden önce ilk olarak görüşme verilerinin geçerlik ve güvenirlik çalışmaları yapılmıştır. Bu bağlamda, ses kayıtları bağımsız bir araştırmacı tarafından dinlenmiş ve görüşme verilerine ilişkin dökümler kontrol edilmiştir. Daha sonra araştırmacı verileri NVivo 8 nitel veri analizi programına yükleyerek verileri çözümlemiştir.

Lincoln ve Guba (1985) nitel araştırmanın niteliğini, nicel araştırmalardaki iç geçerlik yerine inandırıcılık; dış geçerlik yerine aktarılabilirlik; iç güvenirlik yerine tutarlık ve dış güvenirlik yerine teyit edilebilirlik kavramlarının kullanılmasıyla artırılabileceğini vurgulamaktadır. Buna göre araştırmanın inandırıcılığı ve teyit edilebilirliği kapsamında araştırmacı tarafından çözümlenen veriler, bir uzman tarafından analiz edilerek temalar biçiminde oluşturulmuştur. Ortaya çıkan temalar boyutunda araştırmacı ve uzmanın görüş ayrılıkları durumu belirlenmiştir. Araştırmacı ve uzman, aynı temayı belirlemiş ya da hiçbir tema 
seçmemişse, bu durum görüş birliği olarak varsayılmakta; farklılıklar ise görüş ayrılığı olarak tanımlanmaktadır. Miles ve Huberman'ın (1994) önerdiği formül (Güvenirlik = (Görüş Birliği / Görüş Birliği + Görüş Ayrılığı) x 100) kullanılmış ve güvenirlik \%85 olarak bulunmuştur. Hesaplanan güvenirlik puanının .70'ten büyük çıkması ile araştırmacı ve uzmanın görüşlerinin tutarlı ve belirlenen temaların güvenilir olduğu sonucuna varılmıştır.

\section{BULGULAR}

Araştırmanın bulguları sunulurken, araştırma amaçlarındaki sıra izlenmiştir. Anlaşılırlığın artması amacıyla, belirlenen temalar numaralandırılmıştır. Buna göre, araştırma sonucunda 8 tema ortaya çıkmıştır.

\subsection{Günümüzde İlkokullarda Teknoloji Eğitimi}

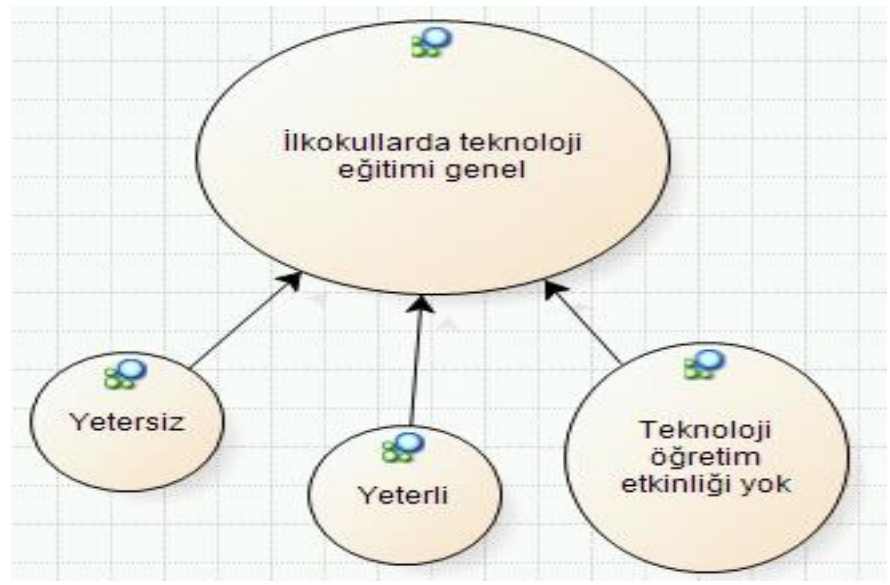

Şekil 1. Günümüzde IIlkokullarda Teknoloji Eğitimi

Şekil 1 incelendiği zaman, öğretmenlerin bir kısmına göre ilkokullarda hiç teknoloji öğretim etkinliği olmadığı görülmektedir. "Okulda öyle bir eğitimimiz yok. Önceden vardı, bilgisayar kullanımı diye." biçiminde görüş belirten bir öğretmen, bu konuyu sade bir biçimde özetlemiştir. Diğer yandan bir öğretmen: 
"Yeterli düzeyde bence." biçimindeki görüşüyle teknoloji eğitiminin yeterli olduğunu belirtirken, bir kısım öğretmenler de teknoloji öğretim etkinliklerinin yer aldığını ancak yetersiz olduğunu belirtmişlerdir. Bir öğretmen bu konuya: “Maalesef şu anda ilkokullarda teknoloji eğitimi yeterli seviyede değil. Hatta neredeyse hiç yok diyebilirim." biçimindeki görüşüyle açıklık getirmiştir.

\section{2. İlkokullarda Teknoloji Eğitimi Etkinlikleri}

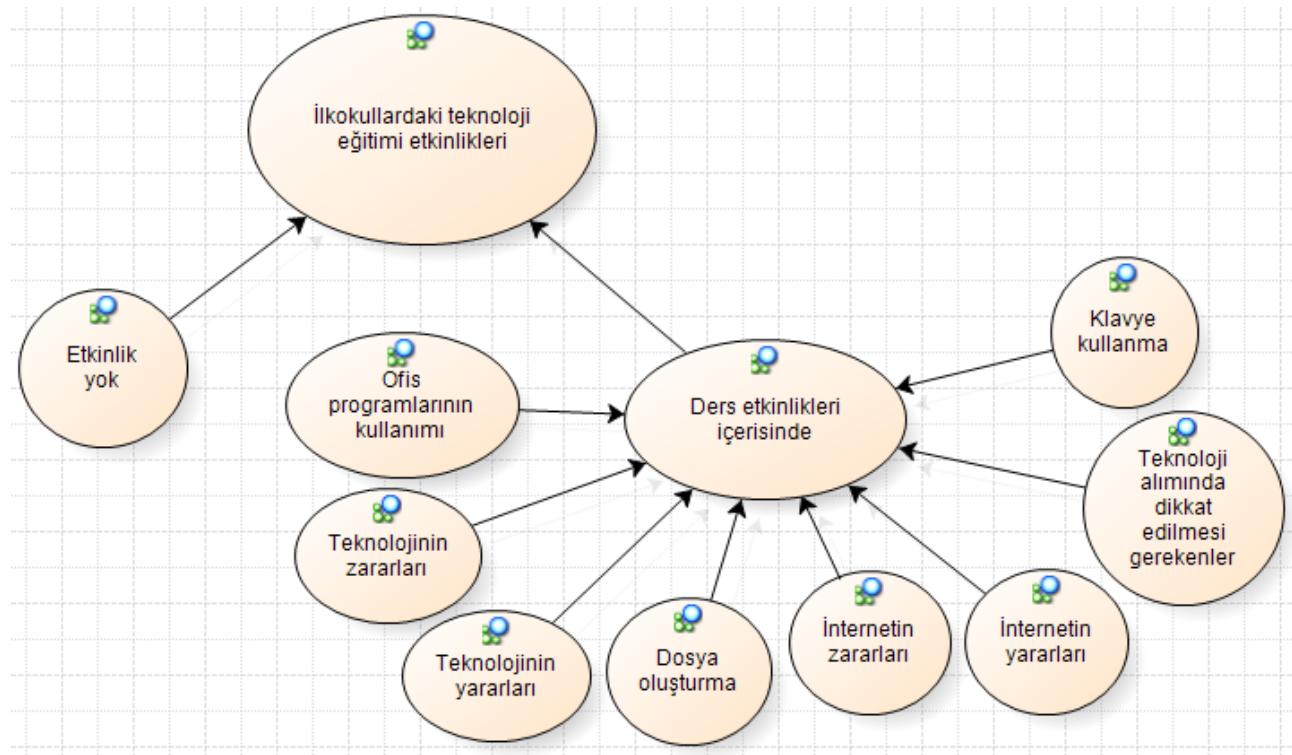

Şekil 2. Illkokullarda Teknoloji Eğitimi Etkinlikleri

Araştırmaya katılan öğretmenlerin bir kısmı teknoloji eğitimi etkinlikleri olmadığını belirtmiş̧tir. Teknoloji eğitimi gerçekleştiren öğretmenler ise bu çalışmalarını ders etkinlikleri içerisinde gerçekleştirmektedir. Bir öğretmen bunu şu cümlelerle ifade etmektedir:

"Örneğin ben çekiliyorum masanın başına geçiyorum köşeye. Yönlendirdiğim öğrenci benim masama geçiyor. Zaten temelde de bazı şeyleri bildiği için yönlendirme ile birlikte o siteye ben onu 
yönlendiriyorum ve o giriyor girdikten sonra işte perdeye yansıtıyor. Yansıttığında işte tanımlamalarla yönlendirme ile birlikte konuyu akıcı hale getiriyorum. Onun görevi bittiğinde ki biraz hızlandırıyoruz süreci biz diğer arkadaşı geliyor. .... Sınıfta ders işlenirken konu anlatılırken hemen hemen bir derste en az 10 veya 12 tane öğrenci bilgisayar başına geçmeyi, bilgisayar başındaki görevini tamamlıyor. Bir sonraki süreçteki derste diğer öğrenciler, hepsine eşit düzeyde bunu yansıtıyorum. Ben bunu yaklaşık olarak ikinci sınıftan itibaren yapıyorum. Birinci sınıfta çok kurcaladıkları için yaklaştırmadım ama onlara bu güveni verdiğim için benim bu sınıfında benim bilgisayarımı benim masamı ortaklaşa biz öğrencilerimizle bu şekilde kullanıyoruz."

Ders etkinlikleri içerisinde öğretilen teknolojiye ilişkin bilgilere bakıldığında, öğretmenlerin kendi çabalarıyla birtakım bilgileri öğrencilere öğretmeye çalıştıkları görülmektedir. Ofis programlarının kullanımını öğretmeye ilişkin olarak bir öğretmen: "Onlara bir Word sayfası açtırdım. İşte adını soyadını sınıfını okulunu yazdırdım. Öyle kaldı, zaman yetmiyor. Çünkü herkese ayrı ders vermen lazım en az beş dakika. Süre yok. Derste de olmadığı için." biçiminde görüşünü ifade ederken; bir diğer öğretmen teknolojinin yararlarını ve zararlarını: "Şunu iyi anlatıyoruz işte, teknolojinin yararları vardır, işte bazen de zararları da oluyor. Ama daha çok yararı var." biçimindeki görüşüyle anlattıklarını ifade etmiştir.

Öğretmenlerin internetin yararlarını ve zararlarını öğretmeye çalıştıkları bulgusuna ulaşılmıştır. Bir öğretmen: “Önce internetin yararları ve zararlarını anlatıyoruz." biçiminde bu konuya ilişkin görüşünü ifade etmiştir. Öğretmenler klavye kullanma etkinliklerini "Ben onlara geçen yıllarda bir şey klavyeyi kullanmayı öğrettim." biçiminde ifade ederken, dosya oluşturma etkinliklerini "İşte bir Word sayfası açtırıyorum. Hiç bilmeyenlere ama. Aç dedim, kapat, işte aç yaz, dosya oluştur gibi basit basit şeyler yaptırdık." biçiminde belirtmiştir. Ayrıca bazı öğretmenlerin teknoloji alımında dikkat edilmesi gereken noktaları da öğretmeye çalıştıkları görülmektedir. Bir öğretmen buna ilişkin olarak: “Alırken şunlara dikkat edelim." biçiminde konuyu anlattığını belirtmiştir. 


\title{
3.3. ilkokul Öğretmenlerinin Teknolojik Yeterlikleri
}

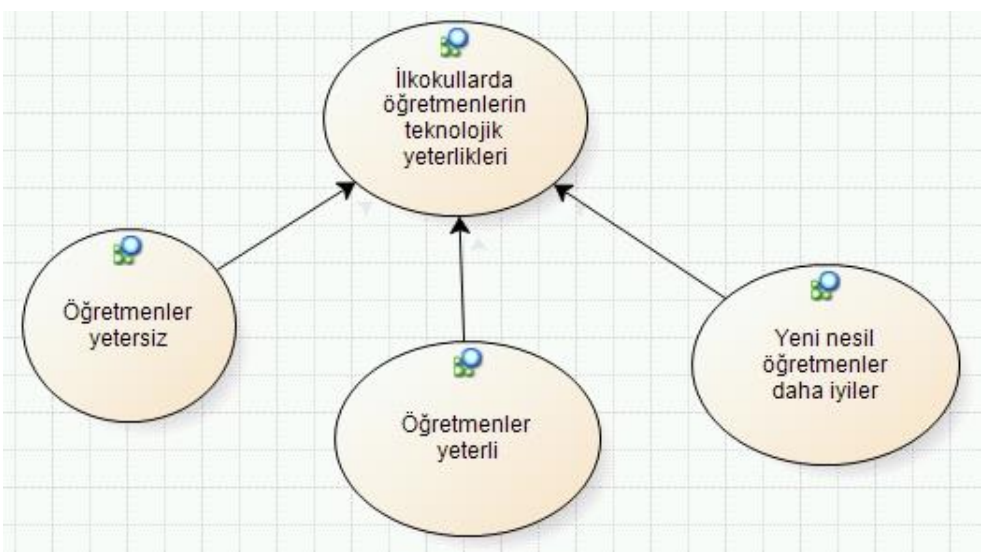

Şekil 3. Illkokul Öğretmenlerinin Teknolojik Yeterlikleri

Teknoloji öğretimi bağlamında, araştırmaya katılan öğretmenlerin bir kısmı öğretmenleri yetersiz görürken yalnızca bir öğretmen yeterli görmüştür. Ancak, öğretmenlerin önemli bir kısmının sürece yeni katılan öğretmenlerin daha fazla yeterli olduklarını belirtmeleri dikkat çekmektedir. Bir öğretmen teknoloji bağlamında yeterli olmalarını: “ilgili bütün öğretmen arkadaşlar ve güncelliyorlar kendilerini. Bizler arasında da çok fazla iletişim var." biçiminde ifade ederken; Öğretmenlerin teknoloji öğretimi bağlamında yetersiz olduklarını bir diğer öğretmen şu biçimde anlatmıştır:

\begin{abstract}
"Öğretmen arkadaşların birçoğunda kendi teknolojik yetersizlikleri olduğu gibi yani bunları öğretme noktasında da birçok sıkıntılar var. Ya bunun sebebi, hem çok fazla program içerisinde de yer almamasından kaynaklanıyor olabilir veya kendilerini yetiştirmemelerinden de kaynaklanıyor olabilir. Ama bir yetersizliğin olduğu düşünülebilir."
\end{abstract}

Yeni yetişen öğretmenlerin teknoloji öğretimi bağlamında daha iyi olduğuna ilişkin olarak bir öğretmen: "Teknoloji öğretimi konusunda çok iyi olanlarını da görüyorum, yani her seviyeden var. Ama, e genel olarak yani, genç 
öğretmenlerin diyelim daha çok bu konuda iyi olduklarını düşünüyorum." biçiminde görüşünü ifade etmiştir.

\section{4. İlkokullarda Öğrencilerin Sahip OIması Gereken Beceriler}

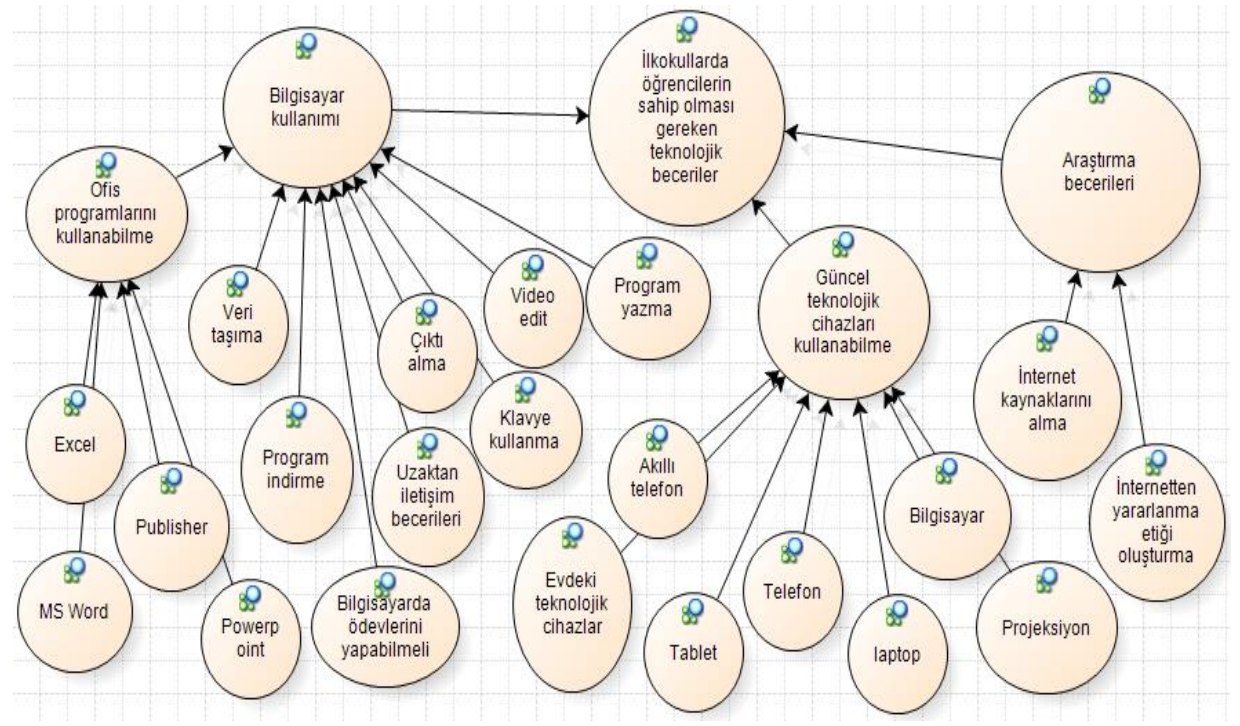

Şekil 4. İlkokullarda Öğrencilerin Sahip Olması Gereken Beceriler

Araştırmaya katılan sınıf öğretmenlerinin görüşlerine göre, ilkokul öğrencilerinin sahip olması gereken teknolojik beceriler üç grupta toplanmaktadır. Bunlar bilgisayar kullanımı, araştırma becerileri ve güncel teknolojik cihazların kullanımıdır. Öğretmenlere göre ilkokul öğrencileri akıllı telefon, tablet, telefon, laptop, bilgisayar, projeksiyon ve evdeki teknolojik cihazları kullanabilmelidir. Öğretmenler "Iş̧te bir bilgisayarı bir laptopu ne bileyim bir akıllı telefon dedikleri telefonu.", "Bir bilgisayarı bir projeksiyonu tanımalı. Açıp kapatmalı." ya da "En basitinden bir telefon çevirerek karşı tarafla iletişim kurabilecek halde olması gerekmektedir." gibi görüşleriyle güncel teknolojik cihazları kullanabilmeyi açıklamışlardır. Bir öğretmen evdeki teknolojik cihazlara ilişkin olarak görüşlerini aşağıdaki biçimde ifade etmiştir: 
"Yine evinde bulunduğu teknolojik aletlerden işte çamaşır makinesi bulaşık makinesi gibi. Bunları çalıştırabilecek yeteneklere sahip olması gerektiğini düşünüyorum. Yani günlük şartlarında kullanabileceği, özellikle temel ihtiyaçlarını karşılarken. Mesela kıyafetleriyle ilgili olarak en basitinden işte çamaşır makinesine atacaksa bunu çalıştırabilmeli diye söyleyebilirim.

Öğretmenlere göre ilkokul öğrencilerinin teknolojik anlamda sahip olması gereken becerilerden bir diğeri araştırma becerileridir. Bir öğretmen bu konuyu aşağıdaki biçimde açıklamıştır:

Biliyorsunuz ki proje ve performans ödevleri veriyoruz öğrencilerin birçoğuna. Bunlarla ilgili genelde araştırma konuları mevcut. Bu araştırma yaparak sadece artık günümüz teknolojisi internete bağlı bir teknoloji haline geldi. Yani burada ne yapabilir çocuk, açıp bilgisayarından bu konuyla ilgili olarak araştırmaları, biliyorsunuz bazı siteler var, bu sitelere girip en azından oradan o bilgiyi sadece okumakla değil onu nasıl alabilir işte getirebilir, bunları bilmesi gerekmektedir yani."

Öğretmenler araştırma becerileri bağlamında internet kaynaklarını alma ve internetten yararlanma etiği oluşturmaya dikkat çekmektedir. Bir öğretmen internet kaynaklarını almayı "Bazı siteler var bu sitelere girip en azından oradan o bilgiyi sadece okumakla değil onu nasıl alabilir işte getirebilir, bunları bilmesi gerekmektedir." biçimindeki sözleriyle anlatırken; bir diğer öğretmen internetten yararlanma etiğini “Oradaki bilgileri indirmek değil ama. Birleştirici etkiyle beraber. Yani nedir bu, öğrendiği konularla beraber, oradaki bilgileri birleştirerek kendisi yeni yazılımlarla beraber kendi fikirlerini birleştirip yeni ürünler ortaya koyabilir." biçiminde ifade etmiştir.

Öğretmenlere göre ilkokul öğrencilerinin sahip olması gereken becerilerden bir diğeri ise bilgisayar kullanma becerileridir. Bilgisayar kullanma becerilerinden biri olan ofis programlarını kullanabilmeye ilişkin olarak bir öğretmen: "Ofis programından Word'ü Excel'i Powerpoint'i, Publisher'ı işte bunları bilse yeter. Zaten bizim hazırlayacağımız materyaller, kaynaklar bunlar." biçiminde ifade etmiştir. Öğretmenler veri taşımayı "Bir flaşa alıp bunu sunum yapmalı sınıfta.", 
çıktı almayı "Çıktı alabilmeli.", program indirmeyi "Program indirebilmeli", klavye kullanmayı "Işste bir klavyeyi kullanabilmelidir.", video düzeltmeyi "Bir videoyu videodan sesi almayı, işte ne bileyim bir o videoya ses eklemeyi .... bilmesi lazım”, uzaktan iletişim becerilerini "iyi iletişim kurabilir. Farklı okullarda online sistemde birbirine bağlanabilir.", program yazma becerisini ise "Program yazabilirler" gibi görüşlerle ifade etmişlerdir.

\section{5. İlkokul Programında Olması Gereken Teknolojik Beceriler}

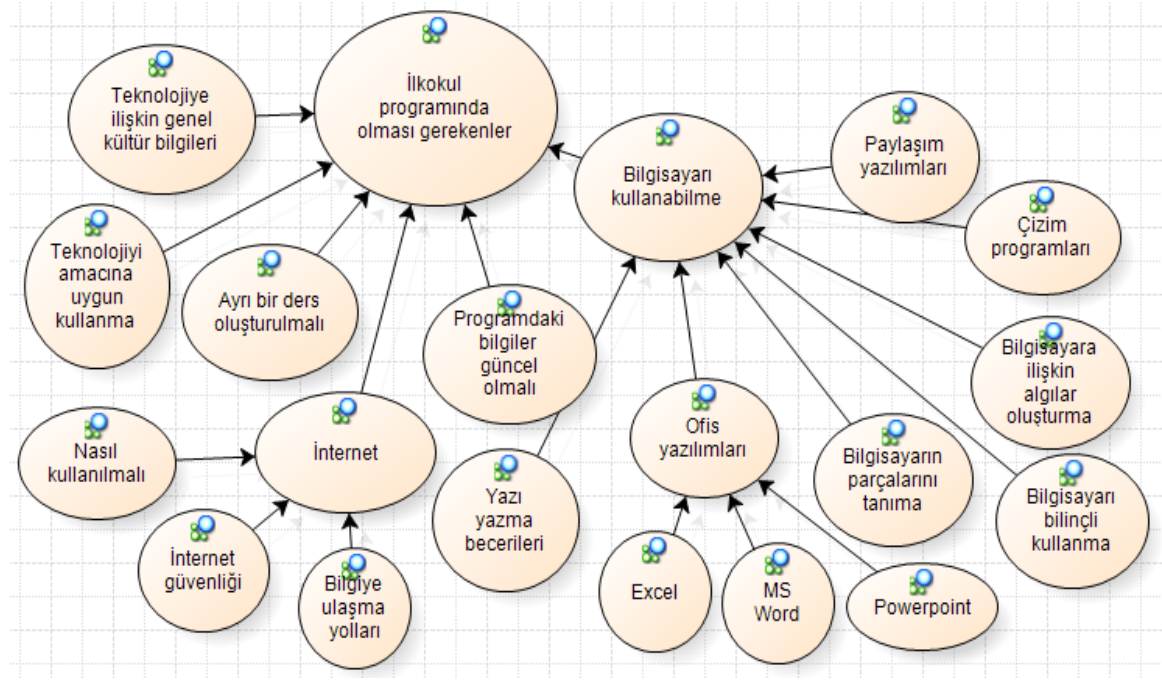

Şekil 5. İlkokul Programında Olması Gereken Teknolojik Beceriler

Öğretmenlerin ilkokul programında olması gereken teknolojik becerilere ilişkin birçok öneride bulundukları görülmektedir. Teknolojiye ilişkin genel kültür bilgileri konusunu bir öğretmen şu biçimde anlatmıştır:

"Şunu düşünüyorum, çocukların yani bütün bu teknolojik ürünleri tek tek nasıl yapıldı ne edildi bilmesi imkânsız ama en azından yani nerede olursa olsun bunları yani topluma hizmeti olan yani milletleri insanları ya da grupları kimse. Onlara karşı biraz daha şey toleranslı, hoşgörüsü artmalı. Onlara daha fazla saygı göstermeli gibi geliyor bana." 
Teknolojiyi amacına uygun kullanma öğretmenlere göre ilkokul programında bulunması gereken bir diğer boyuttur. Öğretmenlerden biri bunu: "Teknolojiyi etkili bir şeklide kullanma, amacına uygun kullanma." biçiminde özetlerken bir diğeri: "Bilgisayarın nasıl kendisine faydalı şekilde kullanacağının da o bilgileri çocuğa verilmesi gerekiyor." biçiminde açıklamıştır. Öğretmenler ayrıca ilkokuldaki teknoloji ile ilgili programın güncelliğini yitirmemesi gerektiğini ifade etmektedir. Bir öğretmen bunu aşağıdaki biçimde ifade etmiştir:

\begin{abstract}
"Ya ben, programı ben yapıyor olsam, programı bir defa yapıp da 10 sene dokunmamak bir defa çok yanlış olur. Teknolojiden bahsediyoruz, programın 2-3 yılda bir güncellenmesi gerekir. Çünkü bir cep telefonu teknolojik bir ürün idi, şimdi ne oldu cep telefonu bir bilgisayara dönüştü. Ama biz hala bu konularla ilgili ders kitaplarında cep telefonu daha yeni çıkmış gibi görünüyor. Son halleri bilinmiyor. Ya da cepte gezen bilgisayarlar bilinmiyor. Çok genel kavramlar, özellikle teknolojiyle ilgili olan derslerin, derslerin programlarının sık sık güncellenmesi gerekiyor."
\end{abstract}

Öğretmenler ayrıca internete ilişkin ilkokul programında bilgiye ulaşma, internet güvenliği ve internetin nasıl kullanacağı gibi bilgilerin de olması gerektiğini düşünmektedir. Öğretmenler bilgiye ulaşmayı "Bilgiye ne yolla nasıl ulaşacağını öğretmek gerekiyor çocuğa. Yani o kafasında tasarladığı şeyleri hangi yolla hangi adreslerden ulaşabileceğini.", internet güvenliğini “Güvenli internet konusunda mutlaka bilgilendirilmeli." ve internetin nasıl kullanacağını bilmeyi "Internet kullanması konusunda da mutlaka bilgilendirilmeli." gibi biçimlerde ifade etmişlerdir.

Öğretmenler teknolojik becerilere ilişkin programda ayrı bir ders oluşturulması gerektiğini düşünmektedirler. Bir öğretmen bu konuya: “Teknoloji eğitimi ya da bilgisayar kullanımı derslerinin tekrar konulması bence faydalı olur. Bence işte, çocuklar kendi kendilerine yetiştirilebiliyorlar ancak, öğretmenlerin ya da okulun bu işte bir katkısı yok." biçimindeki görüşleriyle ışık tutarken, bir diğer öğretmen bu konuyu şu biçimde açıklamıştır: 
"Ders olmalı. Eğer ders olmazsa ne olur işte bu konuyu iyi bilen teknoloji iyi bilen, orta düzeyde bilen veya işte orta düzeyin biraz daha altında bilen, kendi çalışmaları doğrultusunda öğrencilerine hissettirmeden konular içerisinde verebilen öğretmenler bunu yapabiliyor. Bunun dışında eğer ders olmazsa bunun dışında öğrenci okulda teknolojik bilgi ve beceri kazanamıor."

Bilgisayarı kullanabilme, öğretmenlere göre ilkokul programında olması gereken bilgiler arasında önemli bir yere sahiptir. Bilgisayarı kullanabilme bağlamında öğretmenler bilgisayarın parçalarını tanıma, bilgisayara ilişkin algı oluşturma, bilgisayarı bilinçli kullanma, yazı yazma becerileri, ofis yazılımları, çizim programları ve paylaşım yazılımları gibi noktalara değinmişlerdir. Öğretmenler bilgisayarın parçalarını tanımayı "Bir bilgisayarı tanımalı. Parçalarını işte monitördür, klavyedir, mousetur.", bilgisayara ilişkin algı oluşturmayı "Bir kere bilgisayarın öğrenci olarak bilgiye kolay ulaşabilecekleri bir kaynak olduğunu bilmeleri gerekiyor.", bilgisayarı bilinçli kullanmayı ise "Bilgisayarı etkili ve doğru kullanma olabilir." biçiminde ifade etmiştir. Öğretmenler yazı yazma becerisini "Değişik bilgileri bir sayfaya aktarabilme, sayfa üzerindeki ayarlamaları yapabilmeleri lazım çocukların." biçiminde, çizim programlarını "Biz daha çok geometri derslerinde ihtiyacımız oluyor. Belki o tür derslerde çizimler üzerine geliştirseler iyi olur." biçiminde, paylaşım yazılımlarını ise "Gerekirse arkadaşlarıyla ödevlerini paylaşarak yapabilmesini istiyorum aynı anda birlikte. Biraz daha o teknikler geliştirilebilir hani bilgi paylaşımı, arkadaşlarıyla birlikte yapabilmesi, grup içinde yapabilmesi." biçiminde aktarmıştır. Ofis yazılımları da öğretmenlere göre bilgisayarı kullanabilmenin içinde yer alan bir boyuttur. Bu boyut içerisinde öğretmenler Excel, Word ve Powerpoint programlarını önermişlerdir. Bir öğretmen bunu “Word'ü kullanabilmeli en azından. Excel'i kullanabilmeli. Bence, sunum yapabilecek. Slayt hazırlamayı öğrenmeli. Bunlar basit şeyler." biçimindeki görüşüyle kısaca özetlemiştir. 


\subsection{Fen ve Teknoloji Dersinin Fen Bilimleri Olarak Değişmesi}

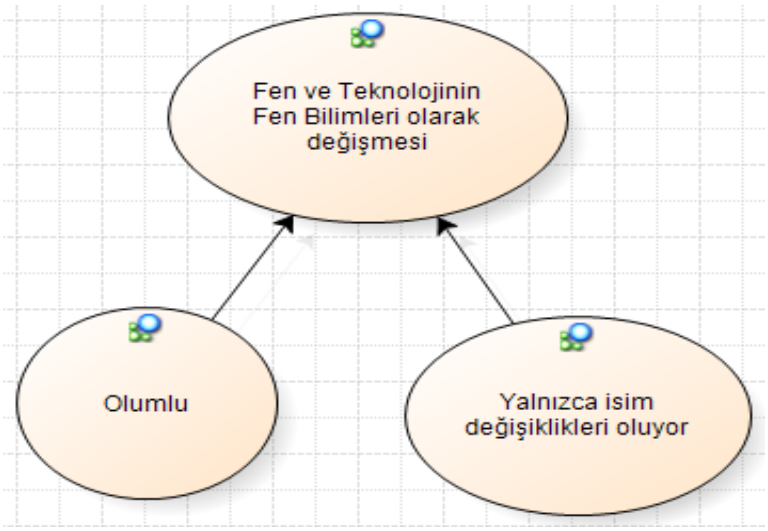

Şekil 6. Fen Ve Teknoloji Dersinin Fen Bilimleri Olarak Değişmesi

Araştırmaya katılan öğretmenlerin görev yaptığı okullarda henüz Fen ve Teknoloji adıyla derslerin uygulanmakta olduğu belirlenmiştir. Öğretmenlere ders değişimi konusundaki görüşleri sorulduğunda, bazıları olumlu görüş belirtirken, bazıları ise yalnızca isim değişiklikleri olduğunu belirtmişlerdir. Bir öğretmen: "Ben o şekilde olmasını daha mantıklı görüyorum. Çünkü teknoloji kısmına bizim sınıflarda çok yer veremediğimizi görüyorum ve Fen dersi olarak işlenmesinin uygulamalı olarak çok daha iyi olacağını düşünüyorum. Çünkü teknoloji kısmına biz çok eğilemiyoruz." biçimindeki görüşüyle değişimin olumlu olduğunu ifade etmiştir. Bir öğretmen: “Adı Fen ve Teknoloji olsa bile, içerik program tamamen Fen Bilimleri. Yani teknolojiyle ilgili hiçbir şey yok." biçimindeki görüşüyle isim değişikliği boyutuna açıklık getirmiştir. 


\section{7. İlkokullarda Teknoloji Eğitimi Bağlamındaki Sorunlar}

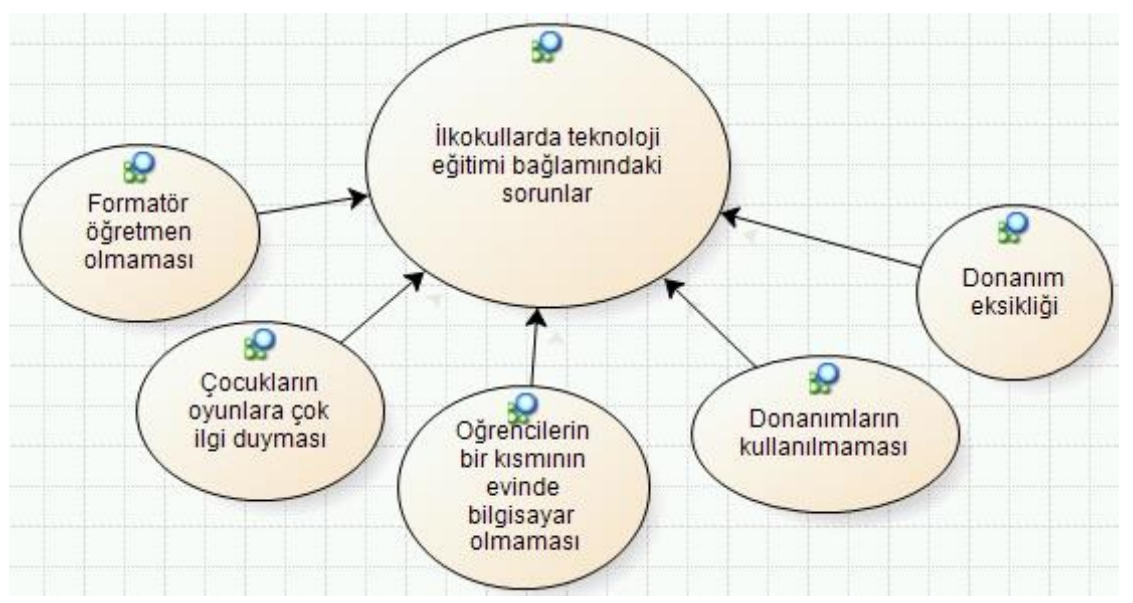

Şekil 7. İlkokullarda Teknoloji Eğitimi Bağlamındaki Sorunlar

İlkokullarda teknoloji eğitiminde farklı boyutlarda sorunların yer aldığı görülmektedir. Formatör öğretmen olmaması bu sorunlardan biridir. Bir öğretmen bu durumu aşağıdaki biçimde açıklamıştır:

"Bilgisayarla ilgili sorun bilgisayar sorunu işte format atmaydı işte karşılaşılan problemleri çözmeydi. Onun defteri vardı tamam o formatörlük zaten kendi dersin dışında yapılan bir şey tamam o dersi girmiyordu sadece formatörlük yapıyordu. O zaman bilgi teknoloji sınıfı vardı, bilgi teknoloji sınıfının bütün sorunlarını hallediyordu, ağla ilgili soruları hallediyordu. Her şeyi hallediyordu. Şimdi bunun dışında ne oldu, bir bilgisayarcıların bir tanesi ile iletişim kuruluyor sıkıştığı yerde ona haber veriliyor o çözüyor. Ama buna çözüm o formatör öğretmen varken pek onlara yönlenmiyorduk."

Çocukların oyunlara çok ilgi duyması bu boyuttaki bir diğer sorun olarak ortaya çıkmıştır. Bir öğretmen bu konuyu: "Çocuğun, bilgisayarı önüne koyduğunuzda ilk yaptığı şey oyun. Hâlbuki biz bilgisayarı hani iletişim haberleşme aracı olarak görüyoruz." biçiminde ifade etmiştir. Öğrencilerin bir kısmının evinde bilgisayar olmaması sorununu ise bir öğretmen: “Öğrenciler açısından da okullarda evet 
var ama evlere de girmesi lazım. Benim öğrencilerim dediğim gibi taşımalı öğrenciler, onlar için büyük sıkıntı oluyor." biçiminde ifade etmiştir.

Okullardaki donanım eksikliği ya da donanım olmasına rağmen kullanılamaması ortaya çıkan diğer sorunlardır. Bir öğretmen donanım eksikliğini "Maalesef hâlâ köy okullarının birçoğunda birçok teknolojik alet kullanılmamakta ve çocukların birçoğu hâlâ teknolojik aletlerle tanışmamaktadır." biçiminde aktarırken; bir diğer öğretmen de donanımların kullanılamamasını aşağıdaki biçimde aktarmıştır:

"Yani bilgisayar sınıf var, oraya bilgisayar getirmişler, öğretmeni var. Ama çocuklar o zaman hiç bilgisayar sınıfına gitmemiş. Mesela hiç laboratuvara inmemiş çocuklar, biliyorum. Ben buraya geldim, 7 yıl önce geldim, işte bir okulda bir görevlendirme aldım. O okula gittim, çocuklar hiç laboratuvara gitmemiş."

\section{8. İlkokullarda Teknoloji Eğitimi Bağlamındaki Öneriler}

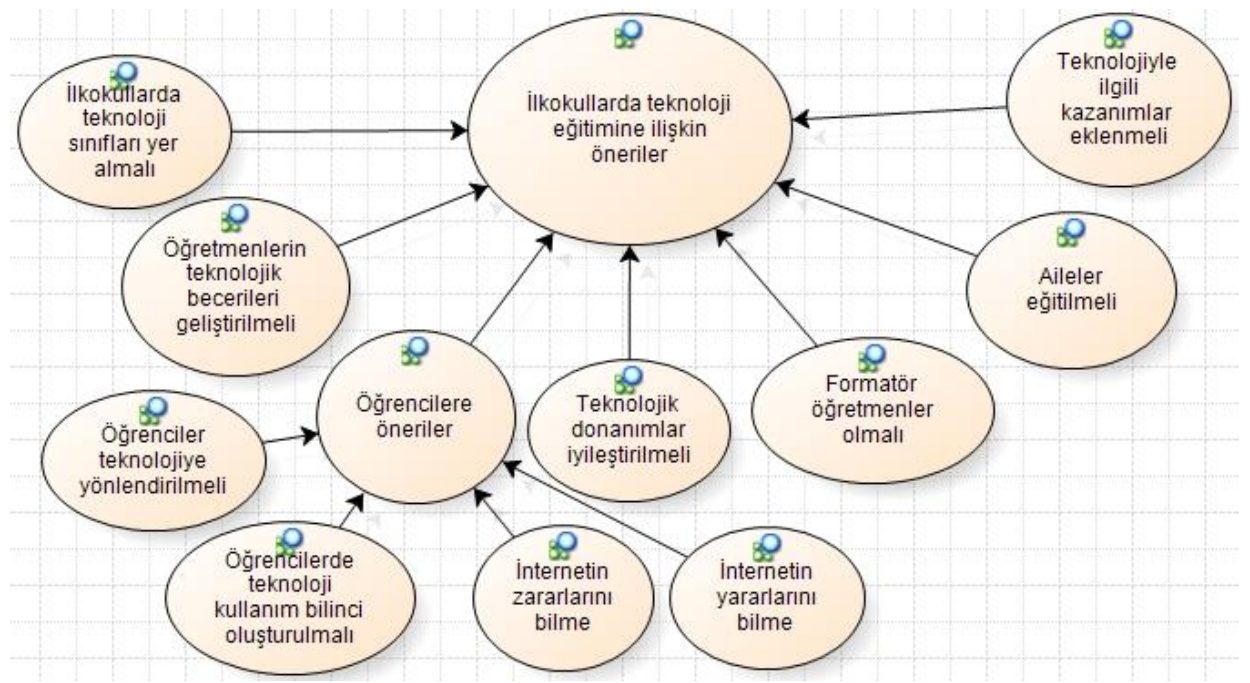

Şekil 8. Illkokullarda Teknoloji Eğitimi Bağlamındaki Öneriler 
Araştırmaya katılan sınıf öğretmenleri, ilkokullarda teknoloji eğitimi kapsamında birtakım öneriler getirmişlerdir. Öğretmenlere göre ilkokullarda teknoloji sınıfları yer almalı, öğretmenlerin becerileri geliştirilmeli, teknolojik donanımlar iyileştirilmeli, formatör öğretmenler geri getirilmeli, aileler eğitilmeli, programa teknolojiyle ilgili kazanımlar eklenmeli ve öğrencileri teknolojiye yönlendirerek teknoloji kullanım bilinci oluşturulmalıdır.

Öğretmenler ilkokullarda teknoloji sınıfları oluşturmayı "Bir teknoloji sınıfı olmalı, yani çocuklara herkese bir bilgisayar düşmeli." biçiminde; öğretmenlerin teknolojik becerilerini geliştirmeyi “öğretmenlerin kendimizi geliştirmemiz olduğumuzla yetinmememiz gerekiyor"; teknolojik donanımların iyileştirilmesini "Bilgisayarlarımızın hızı yavaş, daha hızlanması gerekiyor." ve formatör öğretmenler olmasını "Bilgisayarla ilgili her tür sıkıntımızda biz hani paylaşacağımız, bize yardımcı olacak kişiler de olması gerekiyor." biçiminde ifade etmişlerdir.

Öğretmenlerin dikkat çektiği bir diğer nokta olan ailelerin eğitilmesi konusunu bir öğretmen: "Gerekirse okulda velilere bile bilgisayar teknolojileri ile ilgili seminerler, kurslar açılması gerektiğine inanıyorum. Bir çocuk sadece kendi başına öğretmenle olmuyor, evde de tekrar gerekiyor." biçiminde ifade ederken; programa teknoloji ile ilgili kazanımlar eklemeyi bir öğretmen: “Kazanımlara da bir şeyler konulması lazım, içeriğe de bir şeyler konulması lazım. Ve buna da kazanım koymadan zaman ayıramıyorsun. Senin hedeflerin, kazanımların farklı. Sen derse girdin mi bir planın var, onun dışına çıkamıyorsun." biçiminde ifade etmiştir.

Öğretmenler öğrenciler bağlamında da öneriler getirmiştir. Bir öğretmen öğrencilerin teknolojiye yönlendirilmesi gerektiğini "Öğrenciyi teknolojiye yönlendirmemiz gerekiyor çünkü artık çağımız teknoloji çağı." biçiminde öne çıkarırken; öğrencilerde teknoloji bilinci oluşturulması gerektiğine bir başka 
öğretmen de "Teknoloji nasıl kullanılabilir diye eğitim verilmeli çocuklarımıza, sınırlama getirilmeli işte belli konularda işte. Bilgisayar deyince ilk düşündüğü şey çocuğun oyun, işte çizgi film. Ama bilgi değil, asla değil." biçimindeki görüşüyle konuya dikkat çekmiştir.

\section{TARTIŞMA ve SONUÇ}

Araştırmada, günümüzde ilkokullardaki teknoloji eğitiminin çoğunlukla yetersiz olduğu ya da hiç yer almadığı ortaya çıkmıştır. Öğretmenler çoğunlukla kendilerini teknoloji öğretimi bağlamında yetersiz görmekte, yeni atanan öğretmenlerin ise bu konuda daha yeterli olduğunu düşünmektedirler. ilkokulda öğretmenlerin bir kısmı teknoloji eğitimi etkinlikleri yapmazken; bir kısmının ise ders etkinlikleri içerisinde teknolojinin yararları ve zararları, internetin yararları ve zararları, klavye kullanma, dosya oluşturma, ofis programları kullanımı gibi konularda eğitim verdikleri sonucu ortaya çıkmıştır.

Fen ve Teknoloji dersinin Fen Bilimleri olarak değişmesi bazı öğretmenlere göre olumlu bir durum iken, bazı öğretmenler için yalnızca isim değişikliği olarak algılanmaktadır. Bu bulgu, Tekbıyık ve Akdeniz tarafından (2008) gerçekleştirilen araştırmada sınıf öğretmenlerinin IIlköğretim Fen ve Teknoloji Dersi Öğretim Programı'nı etkili bulmaları ve bu durumda eski programı tercih etmedikleri bulgusuyla farklılık göstermektedir.

Araştırmaya katılan öğretmenlere göre, ilkokul öğrencileri birçok teknolojik beceriye sahip olmalıdır. Bunlar arasında ofis programlarını kullanma, veri taşıma, çıktı alma, klavye kullanma gibi bilgisayar becerilerinin yanı sıra tablet, akıllı telefon ve dizüstü bilgisayar gibi güncel teknolojik cihazları kullanma ile teknolojiye bağlı araştırma becerileri yer almaktadır. Öğretmenler, ilkokul programında teknolojiye ilişkin genel kültür bilgileri, teknolojiyi amacına uygun kullanma, internet ve bilgisayar gibi bilgilerin öğretilmesinin önemle üzerinde 
durmuşlardır. Öğretmenler bilgisayar bağlamında ofis yazılımları, bilgisayarın parçalarını tanıma, yazı yazma, bilgisayarı bilinçli kullanma gibi boyutlara değinmişlerdir. Ayrıca öğretmenler programdaki bilgilerin teknolojideki gelişmelere uygun bir biçimde sürekli güncellenmesi gerektiğini belirtmiştir. Buna göre, öğretmenlerin teknolojinin yararları noktasında öğrencilerin gerekli eğitimi almasını vurguladıkları ve eğitim programlarında da bu konuda gerekli etkinliklerin yapılmasına yönelik görüşler belirttikleri söylenebilir.

Öğretmenlere göre ilkokullarda teknoloji eğitimi bağlamında öne çıkan sorunlar formatör öğretmen olmaması, çocukların oyunlara çok ilgi duyması, çocukların bir kısmının evinde bilgisayar olmaması, okullarda donanım olmaması ya da olan donanımların kullanamamasıdır. Bu bulgu, Buluş Kırıkkaya (2009) tarafından gerçekleştirilen araştırmada ortaya çıkan, Fen ve Teknoloji programına geçiş sonrasında araç gereç ve donanım eksikliği nedeniyle öğretmenlerin programı uygulamada sorunlar yaşaması bulgusuyla benzerlikler göstermektedir. Ayrıca benzer biçimde, Erdoğan (2007) tarafından gerçekleştirilen bir araştırmada da, Fen ve Teknoloji programının etkili bir biçimde uygulanabilmesi için, altyapı ve materyal eksikliklerinin ortadan kaldırılması, kaynak malzemelerin yeterli düzeyde olması gibi boyutların önem taşıdığı bulunmuştur. Yine Öz (2007) tarafından gerçekleştirilen bir çalışmada, Fen ve Teknoloji programının uygulanması sırasında en çok öne çıkan sorunların okullardaki araç gereçlerin yetersiz olması, program hakkında yeterli bilgilendirme yapılmamış olması ve kılavuz kitapların öğretmenlere zamanında ulaştırılmaması biçiminde bulgusuna ulaşılmıştır. Bu durum, yapılan teknolojik yeniliklerin eğitim kurumlarından eğitim programlarına; öğretmenlerden öğrencilere kadar farklı boyutlarda düşünülerek planlanmasının önemli olduğu biçiminde açıklanabilir.

Ayrıca araştırmada sınıf öğretmenleri, ilkokullarda teknoloji eğitimi kapsamında teknoloji sınıfları oluşturma, öğretmenlerin becerilerini geliştirme, teknolojik 
donanımları iyileştirme, formatör öğretmen sistemini getirme, programa teknoloji ile ilgili kazanımlar ekleme, aileleri eğitme ve çocukları teknoloji alanında bilinçlendirerek onları teknolojiye yönlendirme konularında önerilerde bulunmuşlardır.

Sonuç olarak, teknoloji eğitiminin ilkokullarda nitelikli bir biçimde verilebilmesi için, sınıf ortamındaki etkinliklerin belirli ölçütlerle gerçekleştirilmesi ve öğrencilerin erken yaşlarda teknolojiden bilinçli bir yararlanabilmeleri için öğretmenlerin ve ailelerin de gerekli özeni göstermeleri oldukça önemlidir. Bu bağlamda yapılan araştırmada, öğretim alanında birer uygulayıcı olan öğretmenlerin görüşleri doğrultusunda ilkokullarda teknoloji eğitimi ele alınmıştır. Araştırmadan elde edilen sonuçlar doğrultusunda, ilkokul programlarına teknoloji boyutu içeren derslerin ya da kazanımların eklenmesi, bunun yanı sıra ilkokul öğretmenlerinin teknolojik becerilerinin geliştirilmesi önerilebilir. Fiziksel ortamlar açısından ise ilkokullardaki teknolojik donanımın iyileştirilerek, yeterli sayıda teknoloji sınıflarının oluşturulması bir başka öneri olarak sunulabilir.

\section{KAYNAKÇA}

Buluş Kırıkkaya, E. (2009). “ilköğretim Okullarındaki Fen Öğretmenlerinin Fen ve Teknoloji Programına İlişkin Görüşleri”. Türk Fen Eğitimi Dergisi, 6(1): 133-148.

Erdoğan, M. (2007). “Yeni Geliştirilen Dördüncü ve Beşinci Sınıf Fen ve Teknoloji Dersi Öğretim Programının Analizi: Nitel Bir Çalışma". Türk Eğitim Bilimleri Dergisi, 5(2): 221-254.

Ersoy, A. (2002). Ilköğretim 4. ve 5. Sınıf Öğrencilerinin Internet Kullanma Durumları. Yayınlanmamış yüksek lisans tezi, Anadolu Üniversitesi Eğitim Bilimleri Enstitüsü, Eskişehir. 
Lincoln, Y.S. ve Guba, E.G. (1985). Naturalistic inquiry. California: Sage Publications.

MEB (2004). Ilköğretim 4.-5. sınıf fen ve teknoloji dersi programı. Ankara: MEB.

MEB (2014). Fen bilimleri dersi (3, 4, 5, 6, 7. ve 8. sınıflar) öğretim programı. 10

Nisan 2014 tarihinde http://ttkb.meb.gov.tr/program2.aspx?islem=2 \&kno=213 adresinden alınmıştır.

Miles, M. B. ve Huberman, A. M. (1994). Qualitative data analysis: An expanded sourcebook. USA: Sage Publications.

Murphy, C. ve Beggs, J. (2003). “Primary Pupils' and Teachers' Use of Computers at Home and School." British Journal of Educational Technology, 34(1): 79-83.

Odabaşı, H. F., Kabakçı, I. ve Çoklar, A. N. (2007). Internet, çocuk ve aile. 2. Baskı, Ankara: Nobel Yayıncılık.

Öz, B.(2007). 2001 Illköğretim Fen Bilgisi Dersi ve 2005 Illköğretim Fen ve Teknoloji Dersi Programlarına İlişkin Öğretmen Görüşleri. Yayınlanmamış yüksek lisans tezi, Çukurova Üniversitesi Sosyal Bilimler Enstitüsü, Adana.

Patton, M. Q. (1987). How to use qualitative methods in evaluation. California: Sage Publications, Inc.

Runswick-Cole, K. (2011). Interviewing. Oualitative methods in psychology a research guide (pp. 88-99). UK: McGraw Hill Open University Press.

Sakarya, S., Tercan, İ. ve Çoklar, A. N. (2011). “ilköğretim Öğrencilerinin İnterneti ve Arama Motorlarını Kullanma Durumları", 5th International Computer \& Instructional Technologies Symposium, 22-24 September, Fırat University, Elazığ-Turkey.

Şahin, A. (2014). Davranış bilimleri enstitüsü. 07.03.2014 tarihinde http://www.dbe.com.tr/tr-TR/Content/Psikoloji_Dunyasi/Makaleler/ 
Cocuk_Psikolojisi/Ilkogretim_Cagi_Cocuklarinda_Guvenli_Internet_K.as px adresinden alınmıştır.

Tavşancıl, E. ve Aslan, E. (2001). İçerik analizi ve uygulama örnekleri. İstanbul: Epsilon Yayınevi.

Tekbıyık, A. ve Akdeniz, A. R. (2008). “ilköğretim Fen ve Teknoloji Dersi Öğretim Programını Kabullenmeye ve Uygulamaya Yönelik Öğretmen Görüşleri”. Necatibey Eğitim Fakültesi Elektronik Fen ve Matematik Eğitimi Dergisi, 2(2): 23-37.

Türkiye İstatistik Kurumu (2013). 06-15 yaş grubu çocuklarda bilişim teknolojileri kullanımı ve medya. 05.03.2014 tarihinde http://www.tuik.gov.tr/PreHaberBultenleri.do?id=15866 adresinden alınmıştır.

Yıldırım, A. ve Şimşek, H. (2013). Sosyal bilimlerde nitel araştirma yöntemleri. 9. Baskı, Ankara: Seçkin Kitabevi.

\section{EXTENDED ABSTRACT}

\section{Introduction}

Examining the literature, it is observed that students become or start to become acquainted with such technologies as Internet and Computers at the school starting age. Today, these technologies include various contents which may endanger the students and make them open to dangers. These technologies are, at the same time, one of the sources which the students can utilize for educational activities and prefer most. Thus, it is of vital importance that the students learn to use these technologies and have the consciousness of how to utilize them; they are provided with a quality education on these technologies at early ages and raised with accurate attainments. 
Main purpose of this study is to examine the status of technology education at primary schools and to reveal the opinions of classroom teachers on technology education. In this study, main purpose of which is to examine the status of technology education at primary schools, qualitative research design is adopted. The participants of the study consist of the classroom teachers who taught the 4th graders of the primary schools in the city center of Giresun province in spring term of 2013-2014 school year. The participants have been chosen through criterion sampling which is one of the purposeful sampling methods. While determining the participants, following criteria were considered: The socio-economic conditions of the schools at which the classroom teachers serve; the fact that the schools at which the classroom teachers serve have at least two 4th grade classrooms; the fact that the teachers have a professional experience of, at least 10 years or more and they taught the 4 th graders at least once. Thus, the primary schools from different socio-economic levels have been chosen and the volunteer teachers who serve at these schools and teach the 4 th graders have been determined to be the participants.

\section{Method}

The data of the study have been gathered through semi-structured interview questions. First of all, draft interview questions were prepared for data gathering tool and presented to two experts for consideration. The semistructured interview questions which were restructured in line with the experts' opinions were asked in a pilot interview with a teacher candidate. In line with the feedbacks from the pilot interview, interview questions were finalized and interviews with 15 classroom teachers were conducted. Interviews were conducted at school environment together with tape recording. Descriptive analysis was utilized in analyzing the data. Before the analysis of the obtained 
data, validity and reliability were tested. Within this context, recordings were listened by an independent researcher and they were controlled. And then, researcher data were loaded in NVivo 8, a qualitative data analysis program, and analyzed. Obtained data were organized in themes. In the study, the formulation proposed by Miles and Huberman (1994) (Reliability= (Agreement / Agreemet + Disagreement) $\times 100$ ) was used and reliability was estimated to be $85 \%$. It was concluded that the opinions of researcher and expert were consistent with the estimated reliability point being above 0.70 .

\section{Findings (Results)}

It is revealed in the study that today, the technology education at primary schools is mostly insufficient or even unavailable. Teachers mostly consider themselves incompetent in terms of technology teaching and think that newly appointed teachers are more competent. While some of the teachers in primary schools do not conduct technology education activities, the others provide education for such fields as benefits and harms of the Internet, keyboard usage, file creation and office programs, within classroom activities. While it is a positive development for some teachers that Science and Technology lesson has changed into Science lesson, others consider it as a name change.

According to the teachers who have participated in the study, students must have various technological skills. Among them are such computer skills as using office programs, data transmission, taking a printout and using a keyboard; such research skills as using contemporary technological devices such as tablets, smart phones and laptop computers. The teachers have emphasized the importance of teaching such areas as general knowledge about technology, the internet, computer technology and relevant use of technology. They address such issues as office programs, familiarization of computer parts, typing and conscious use of computer. Furthermore, they state that information in the 
curriculum must be updated continuously based on the related developments. Accordingly, it can be suggested that the teachers emphasize the providing students with required technology education based on its advantages and support the conduct of the required activities in curriculums.

According to the teachers, the prominent problems as part of teaching technology in primary schools are that some of the children do not have computers at home and lack of formatter teachers, children's strong interest in computer games, lack of sufficient hardware at schools or nonuse of them. Furthermore, the classroom teachers have made the suggestions of forming technology classrooms within the context of technology education at primary schools, improving teachers' skills and technological infrastructure, employing formatter teacher system, adding educational attainments related to technology in curriculum, training parents and raising children's awareness about technology.

\section{Conculusion and Discussion}

In conclusion, in order to provide quality technology education at primary schools, it is essential that the activities related to the technology in classroom environment be conducted at a certain degree and teachers as well as parents exercise due care for children to utilize technology consciously at early ages . Within this context, technology education at primary schools in line with the opinions of teachers who are practitioners in the field of teaching has been discussed in the study. Based on the results obtained from the study, adding subjects or attainments which include technology to primary school curriculums and improving technological skills of primary school teachers can be suggested. As for physical environments, it can be suggested that the technological infrastructure at primary schools be improved and sufficient number of technology classrooms be organized. 